\title{
Absence of OATP1B (Organic Anion-Transporting Polypeptide) Induction by Rifampin in Cynomolgus Monkeys: Determination Using the Endogenous OATP1B Marker Coproporphyrin and Tissue Gene Expression
}

\author{
Yueping Zhang, Cliff Chen, Shen-Jue Chen, Xue-Qing Chen, David J. Shuster, \\ Pawel D. Puszczalo, R. Marcus Fancher, Zheng Yang, Michael Sinz, and Hong Shen \\ Departments of Metabolism and Pharmacokinetics (Y.Z., C.C., R.M.F., Z.Y., M.S., H.S.), Discovery Toxicology (S.-J.C.), \\ Discovery Pharmaceutics (X.-Q.C.), and Veterinary Sciences (D.J.S., P.D.P.), Bristol Myers Squibb Company, Princeton, \\ New Jersey
}

Received May 29, 2020; accepted July 14, 2020

\begin{abstract}
Organic anion-transporting polypeptide (OATP) 1B induction is an evolving mechanism of drug disposition and interaction. However, there are contradictory reports describing OATP1B expression in hepatocytes and liver biopsies after administration of an inducer. This study investigated the in vivo effects of the common inducer rifampin (RIF) on the activity and expression of cynomolgus monkey OATP1B1 and OATP1B3 transporters, which are structurally and functionally similar their human OATP1B counterparts. Multiple doses of oral RIF (15 mg/kg) resulted in a steady 3.9-fold increase of CYP3A biomarker, $4 \beta$-hydroxycholesterol $(4 \beta \mathrm{HC})$, in the plasma samples collected before each RIF dose during the treatment period (i.e., predose). In contrast, the predose plasma levels of OATP1B biomarkers coproporphyrin (CP) I and CPIII did not change when compared with RIF treatment. The trough concentration, area under plasma concentration-time curve (AUC), and half-life of RIF decreased markedly during RIF treatment, suggesting that RIF induced its own clearance. Consequently, RIF treatment increased CPI and CPIII AUCs substantially after a single administration and, to a lesser extent, after multiple administrations compared with preadministration AUCs. In addition, OATP1B1 and OATP1B3
\end{abstract}

mRNA expressions were not modulated by RIF treatment (0.85-1.3-fold), whereas CYP3A8 expression was increased 3.7-5.0-fold, which correlated well with the predose levels of $\mathrm{CP}$ and $4 \beta \mathrm{HC}$. Rifampin treatment showed 2.0-3.3-fold increases in $\mathrm{P}$-glycoprotein ( $\mathrm{P}$-gp), breast cancer resistance protein (BCRP), and multidrug resistance-associated protein 2 (MRP2) expression in the small intestine. Collectively, these findings indicate that monkey OATP1B and OATP1B3 are not induced by RIF, and further investigation of OATP1B induction by RIF and other nuclear receptor activators in humans is warranted.

\section{SIGNIFICANCE STATEMENT}

In this study, combined endogenous biomarker and gene expression data suggested that RIF did not induce OATP1B in cynomolgus monkeys. For the first time, the study determines transporter gene expression in the nonhuman primate liver, gut, and kidney tissues after administration of RIF for 7 days, leading to a better understanding of the induction of OATP1B and other major drug transporters. Finally, it provides evidence to strengthen the claim that coproporphyrin is a suitable endogenous probe of OATP1B activity.

\section{Introduction}

There is increasing recognition that members of the hepatic organic anion-transporting polypeptide (OATP) subfamily are among the most important of all of the human drug transporters. This is because they are the most abundant forms of hepatic transporters and have the ability to transport a variety of drugs of clinical and toxicological importance (Niemi, 2007;

This study is supported by Bristol Myers Squibb Company. https://doi.org/10.1124/jpet.120.000139.
Shitara et al., 2013). In addition, OATP1B has been described as a "rate-determining step" in hepatic clearance for several dual-transporter and enzyme drug substrates (Watanabe et al., 2010; Maeda et al., 2011; Patilea-Vrana and Unadkat, 2018). OATP1B1 and OATP1B3 transporters have overlapping substrate specificities and are separate gene products that have been categorized into a subfamily with common structural and regulatory elements. In mammalian species, although there are two genes in the human and monkey subfamily OATP1B, only one gene was identified in other species (e.g., human and monkey OATP1B1 and OATP1B3 as

ABBREVIATIONS: $A U C$, area under plasma concentration-time curve; $A U C_{0-24 \mathrm{~h}}, A U C$ from time 0 to 24 hours; $\mathrm{BCRP}$, breast cancer resistance protein; $4 \beta \mathrm{HC}, 4 \beta$-hydroxycholesterol; $\mathrm{CP}$, coproporphyrin; DDI, drug-drug interaction; FXR, farnesoid X receptor; HPLC, high-performance liquid chromatography; LC, liquid chromatography; LC-MS/MS, liquid chromatography-tandem mass spectrometry; LXR, liver X receptor; MDR1, multidrug resistance protein 1; MRP, multidrug resistance-associated protein; NME, new molecular entity; OATP, organic anion-transporting polypeptide; P-gp, P-glycoprotein; PCR, polymerase chain reaction; PPIA, peptidylprolyl isomerase A; PXR, pregnane X receptor; QC, quality control; RIF, rifampicin; UGT, UDP-glucuronosyltransferase. 
compared with rodent OATP1B2) (Hagenbuch and Stieger, 2013; Shen et al., 2013). Cynomolgus monkey and human OATP1B1 and OATP1B3 are structurally related isotransporters $(91.9 \%$ and $93.5 \%$ identical, respectively) with very similar substrate specificity (Shen et al., 2013; Takahashi et al., 2019). Consequently, cynomolgus monkeys are used as a preclinical model to gain mechanistic insight into and predict clinical OATP1B-mediated DDIs using in vitro data (Shen et al., 2013, 2016; Chu et al., 2015; Kosa et al., 2018; Ufuk et al., 2018; Niu et al., 2019).

Drug interactions may reduce drug-metabolizing enzyme and transporter activities through inhibition or may increase their activities through induction. Induction of enzymes and transporters can, in clinical practice, lead to reduced absorption and enhanced clearance of the drug itself and/or of a coadministered drug, thereby resulting in decreased drug exposure and loss of therapeutic efficacy (Chu et al., 2009; Turk et al., 2019). Compared with drug-metabolizing enzymes, much less is known of the induction of drug transporters. Only a few transporters in the ATP-binding cassette family, including P-glycoprotein (P-gp), also known as multidrug resistance protein 1 (MDR1) and multidrug resistance-associated protein (MRP) 2, have been shown to be inducible in monkeys and humans (Niemi et al., 2003; Sinz et al., 2008; Elmeliegy et al., 2020; Rodrigues et al., 2020; Zamek-Gliszczynski et al., 2020). The effect of commonly used inducers on the expression and functional activity of OATP1B is poorly understood. Reports that describe the induction of OATP1B as decreased systemic exposure of probe substrates and increased $\mathrm{mRNA}$ and protein levels are limited and conflicting. For example, multiple doses of $450 \mathrm{mg}$ rifampin (RIF), a strong pregnane $\mathrm{X}$ receptor (PXR) agonist, did not affect the area under plasma concentration-time curve $(A U C)$ of rosuvastatin in humans (Zhang et al., 2008) (Crestor label: https://www.accessdata.fda.gov/drugsatfda_docs/ label/2017/021366s037lbl.pdf). In contrast, dose-dependent decreases in rosuvastatin and pravastatin $A U C$ after multiple RIF doses (2-600 mg) led to decreases of 2.7- and 2.4-fold, respectively (Lutz et al., 2018). RIF at $600 \mathrm{mg}$ also reduced the exposures of midazolam and dabigatran, probe drugs of CYP3A, and P-gp by 11.6- and 3.0-fold, respectively, in the same subjects (Lutz et al., 2018). In addition, OATP1B mRNA expression in liver biopsy specimens was not changed by multiple administration of $600 \mathrm{mg}$ RIF in 10 healthy subjects (Marschall et al., 2005), whereas the moderate PXR inducer, carbamazepine, increased OATP1B1 and OATP1B3 mRNA expression approximately 2 -fold in the liver biopsy specimens of two epileptic subjects (Oscarson et al., 2006). Notably, there are major challenges in clinical OATP1B induction investigation. OATP1B drug probes, such as statins, are not specific to OATP1B, and they also present as substrates of induced CYP, $\mathrm{P}$-gp, and MRP2. In addition, despite the most direct way to assess induction by profiling transporter expression, most investigators avoid developing study protocols necessitating biopsy procedure because of inconvenience. At the same time, most researchers are forced to conduct in vitro OATP induction studies with human primary hepatocytes and hepatic cell lines. Hence, an understanding of the in vivo function and expression of OATP1B after administration of inducers for greater than 7 days is of substantial interest.

For a long time, RIF, has been considered a model drug of choice for measuring inductive properties of key enzymes and transporters, such as CYP3A, CYP2B6, UGT1A1, and P-gp, because of its strong potential to activate PXR (Strolin Benedetti and Dostert, 1994; Finch et al., 2002; Niemi et al., 2003; Sinz, 2013; Elmeliegy et al., 2020). The Food and Drug Administration recommends using the decrease in $A U C$ of new molecular entity (NME) in healthy volunteers before and after administration of multiple RIF doses to determine the worst-possible risk scenario when the in vitro data indicate that the NME is a substrate of CYP2B6, CYP2C, and CYP3A (https://www.fda.gov/drugs/drug-interactions-labeling/drugdevelopment-and-drug-interactions-table-substrates-inhibitorsand-inducers\#table2-3). RIF is also a well-known inhibitor of OATP1B and is associated with many DDIs. The pharmaceutical industry is working toward the use of putative endogenous biomarkers, such as $4 \beta$-hydroxycholesterol ( $4 \beta \mathrm{HC}$ ), in place of probe drugs for CYP3A induction investigation to avoid unnecessary administration of drugs to subjects (Diczfalusy et al., 2011; Kasichayanula et al., 2014; Li et al., 2014; Mao et al., 2017; Tahara et al., 2019). The in vivo induction potential of an NME could be investigated in preclinical animal toxicity and early clinical pharmacokinetic studies with repeated dosing using endogenous biomarkers. Recently, plasma concentrations of coproporphyrin (CP) I and CPIII, substrates for monkey and human OATP1B, have been proposed as endogenous probes for OATP1B activity in drug discovery and development. Evaluation of plasma CP level could assess the role of OATP1B in complex DDIs involving multiple elimination pathways (Lai et al., 2016; Shen et al., 2016; Jones et al., 2020; Mori et al., 2020).

The present study was designed to measure temporal variations of CP and gene expression of OATP1B as well as examine the inductive effects of RIF on OATP1B1 and OATP1B3 in cynomolgus monkeys. Data reported in this study provide useful information regarding cynomolgus monkey OATP1B induction capability by a potent PXR agonist.

\section{Materials and Methods}

\section{Chemicals and Reagents}

CPI and CPIII were purchased as dihydrochloride salts from Frontier Scientific (Logan, UT). Rifampin, $4 \beta \mathrm{HC}$, cholesterol, highperformance liquid chromatography (HPLC)-grade methanol, acetonitrile, and water were purchased from Sigma Aldrich (St. Louis, MO). ${ }^{15} \mathrm{~N}_{4}$-CPI (20 nM) and $\mathrm{d}_{3}$-RIF were purchased from Toronto Research Chemicals (North York, ON, Canada) and used as the internal standard for CPI bioanalysis. $d_{8}$-CPIII was synthesized at Bristol Myers Squibb Company (Princeton, NJ). The cynomolgus monkey plasma stripped four times with charcoal was purchased from Bioreclamation IVT (Westbury, NY). All other reagents and chemicals used were of the highest grade commercially available.

\section{Animals}

Male and female cynomolgus (Macaca fascicularis) monkeys (approximately 4-8 years of age; $3.1-7.1 \mathrm{~kg}$ ) were used for these studies, and all animal experiments were performed at the Bristol Myers Squibb animal facility. Monkeys were housed in a temperaturecontrolled environment at $64-84^{\circ} \mathrm{F}, 45 \%-70 \%$ humidity, and a 12-hour (h) light/dark cycle. Monkeys were provided a normal food schedule before study (meals at 8:00 AM and 11:00 AM) and were allowed free access to water. On the day of study, animals were fed at approximately 4 hours postdose and allowed water ad libitum. The experimental protocol was approved by the Institutional Animal Care and Use Committee of Bristol Myers Squibb. Animals were treated in accordance with the Guide for the Care and Use of 
Laboratory Animals (Institute of Laboratory Animal Resources, Commission on Life Sciences, National Research Council, Washington, DC, 1996).

\section{Study Design}

Experiment 1 (Endogenous Biomarker). The endogenous biomarker experiment was carried out in the same three male cynomolgus monkeys as a crossover study over three periods (Fig. 1A).

Part 1: During a baseline period (day 1 through day 7), blood samples were collected at 8:00 AM on day 1, day 2, day 3 , and day 5 to determine baseline plasma levels $4 \beta \mathrm{HC}$, CPI, and CPIII. On day 4 , each monkey received $2 \mathrm{mg} / \mathrm{kg}$ midazolam hydrochloride syrup by oral gavage followed by a sterile water rinse, and blood samples were collected at $0.17,0.33,0.5,1,2,3,4,6,8$, and 24 hours postdose in $\mathrm{K}_{2}$-EDTA-containing tubes. Blood samples were stored on wet ice before being centrifuged to obtain plasma $\left(500 \mathrm{~g}, 10\right.$ minutes at $\left.4^{\circ} \mathrm{C}\right)$. The resultant plasma was stored at $-70^{\circ} \mathrm{C}$ until analysis.

Part 2: From day 8 to day 19 (RIF treatment period), each monkey received an oral dose of $15 \mathrm{mg} / \mathrm{kg}$ RIF [as a solution in $0.01 \mathrm{~N}$ hydrochloric acid] daily. The dose of $15 \mathrm{mg} / \mathrm{kg}$ was selected because we previously reported that the systemic exposure after single and multiple doses of $15 \mathrm{mg} / \mathrm{kg}$ RIF in cynomolgus monkeys was comparable to that in humans (Kim et al., 2010; Shen et al., 2013). On day 15, the three animals were coadministered $2 \mathrm{mg} / \mathrm{kg}$ midazolam orally with RIF. A single blood sample was collected at 8:00 AM prior to each RIF dose during this period, except for days 8 and 15. On day 8 and day 15 , blood samples were withdrawn from the animals at 0 (predose), 0.17 , $0.33,0.5,1,2,3,4,6,8$, and 24 hours after each RIF administration.

Part 3: During the washout period (day 20 through day 26), no RIF was administered to the animals. On day 25 , the monkeys received an oral dose of $2 \mathrm{mg} / \mathrm{kg}$ midazolam. Consequently, blood samples were collected from the animals at 0 (predose), 0.17, 0.33, 0.5, 1, 2, 3, 4, 6, 8, and 24 hours after midazolam administration. In addition, blood collections were conducted at 8:00 AM on day 20 through day 26 to measure plasma $4 \beta \mathrm{HC}$, CPI, and CPIII concentrations.

Experiment 2 (Gene Expression). In a separate experiment, transporter and enzyme gene expressions were determined in target tissues (liver, small intestine, and kidney), Table 1. 0.01N hydrochloric acid (vehicle control) or RIF $(15 \mathrm{mg} / \mathrm{kg}$ ) was administered once daily for 7 days (day 8 through day 14; treatment period) to three female cynomolgus monkeys via oral gavage $(n=3$ per group)
(Fig. 1B). Animals were randomly assigned to control or treatment groups. Animals were not fasted for blood sample collections. A single blood sample was collected at 8:00 AM on days 1, 7, 9, 10, 11, 12, 13, and 15 for CPI and CPIII measurement. Blood samples were also collected after the first (day 8) and seventh RIF dose (day 14) of the dosing phase at $0.5,2,4$, and 6 hours postdose for biomarker and drug pharmacokinetic evaluation. Blood collection, processing, and storage were performed as described above. On day 15, at approximately 24 hours after the last treatment dose, animals were sacrificed according to schedule of the Animals (Scientific Procedures) Act 1986. The liver, small intestine, and kidney cortex were harvested to allow determination of the effects of RIF on transporter and enzyme expression after multiple RIF doses. For small intestine, the first 4 inches of jejunum (proximal section of jejunum), approximately, were excised and perfused with $25 \mathrm{ml}$ of ice-cold saline to remove food contents. The segment was cut lengthwise $\left(4^{\circ} \mathrm{C}\right)$, and the intestinal lining was removed by scraping. Tissues were placed immediately in cryotubes and stored at $-70^{\circ} \mathrm{C}$ until analysis.

\section{Quantification of RIF, CPI, and CPIII in Plasma by Liquid Chromatography-Tandem Mass Spectrometry}

The plasma concentrations of RIF, CPI, and CPIII were measured in plasma samples using liquid chromatography-tandem mass spectrometry (LC-MS/MS) assays described previously with slight modifications (Kandoussi et al., 2018; Zhang et al., 2019). A lower limit of quantification of $0.078 \mathrm{nM}$ was achieved for both CPI and CPIII using optimized sample extraction and LC-MS/MS conditions. The assay demonstrated excellent accuracy and precision. The $R$ from four standard curves was greater than 0.990 , and accuracy and precision were confirmed within $15.0 \%$ of quality controls at low, middle, and high concentrations. There was no indication of matrix instability for 98 days in surrogate matrix and 400 days in plasma samples protected from light during storage, suggesting no apparent stability issues (Kandoussi et al., 2018).

Throughout the entire sample extraction, appropriate protections were taken to minimize sample exposure to ambient light. All standards and quality controls (QCs) were made in charcoal-stripped monkey plasma. Standard and QC mixtures of the analytes were made to encompass a range of concentrations (1.5-10,000 nM, RIF; 0.156-40 nM, CPI; 0.156-40 nM, CPIII). Aliquots of $50 \mu \mathrm{l}$ of plasma samples, standards, and QCs were mixed with $50 \mu \mathrm{l} 1 \mathrm{M}$ formic acid.

\section{A Experiment 1 (Endogenous biomarker)}

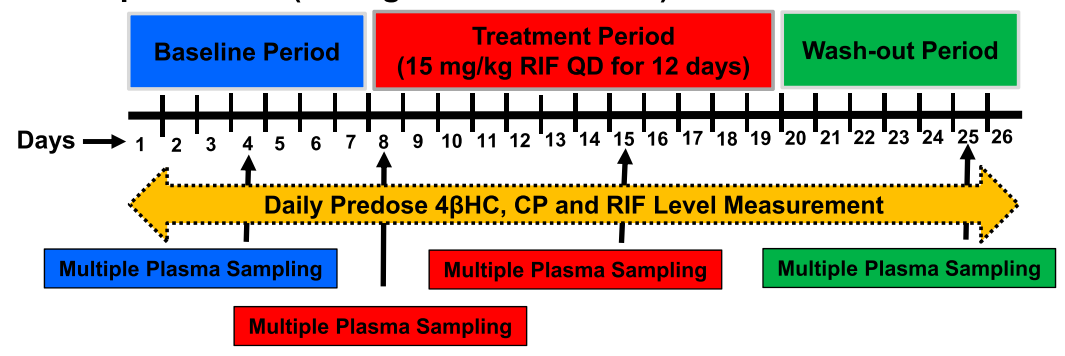

\section{B Experiment 2 (Gene expression)}

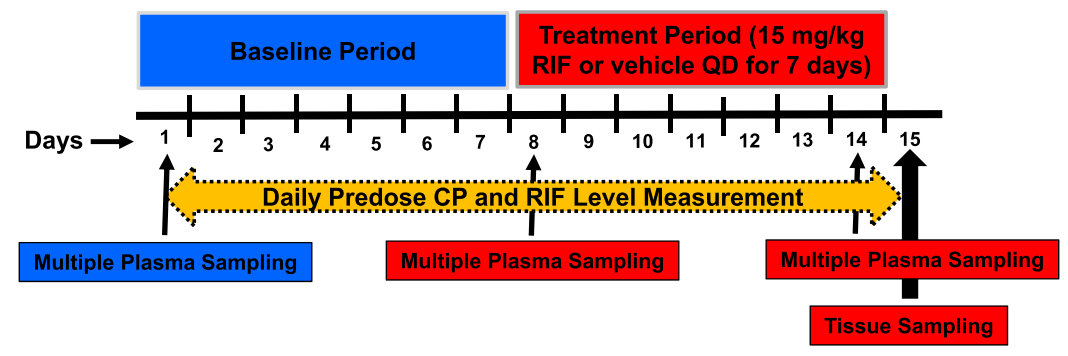

Fig. 1. Schematic diagram of experimental procedure. A single plasma sample was collected for almost every day over an entire study course for endogenous biomarker measurement in both experiments [predose samples were collected before each RIF dose during treatment period (i.e., 0 hours)]. In addition, in experiment 1 (endogenous biomarker) (A), sequential plasma samples were collected from 0.17 to 24 hours on day 4 (before the RIF treatment; $15 \mathrm{mg} / \mathrm{kg}$ RIF daily dose for 12 days; blue box), day 8 (after the first RIF dose; red box), day 15 (after the eighth RIF dose; red box), and day 25 (6 days after the last RIF dose; green box) for biomarker and RIF pharmacokinetics determinations in cynomolgus monkeys $(n=3)$. In subsequent gene expression experiment (experiment 2) (B), the liver, proximal jejunum, and kidney tissue specimens were collected for mRNA expression analysis after oral administration of vehicle or RIF ( $15 \mathrm{mg} / \mathrm{kg}$ per day) for 7 consecutive days in cynomolgus monkeys $(n=3$ per group). QD, once a day. 
TABLE 1

Primers and probes used for real-time quantitative reverse-transcription PCR

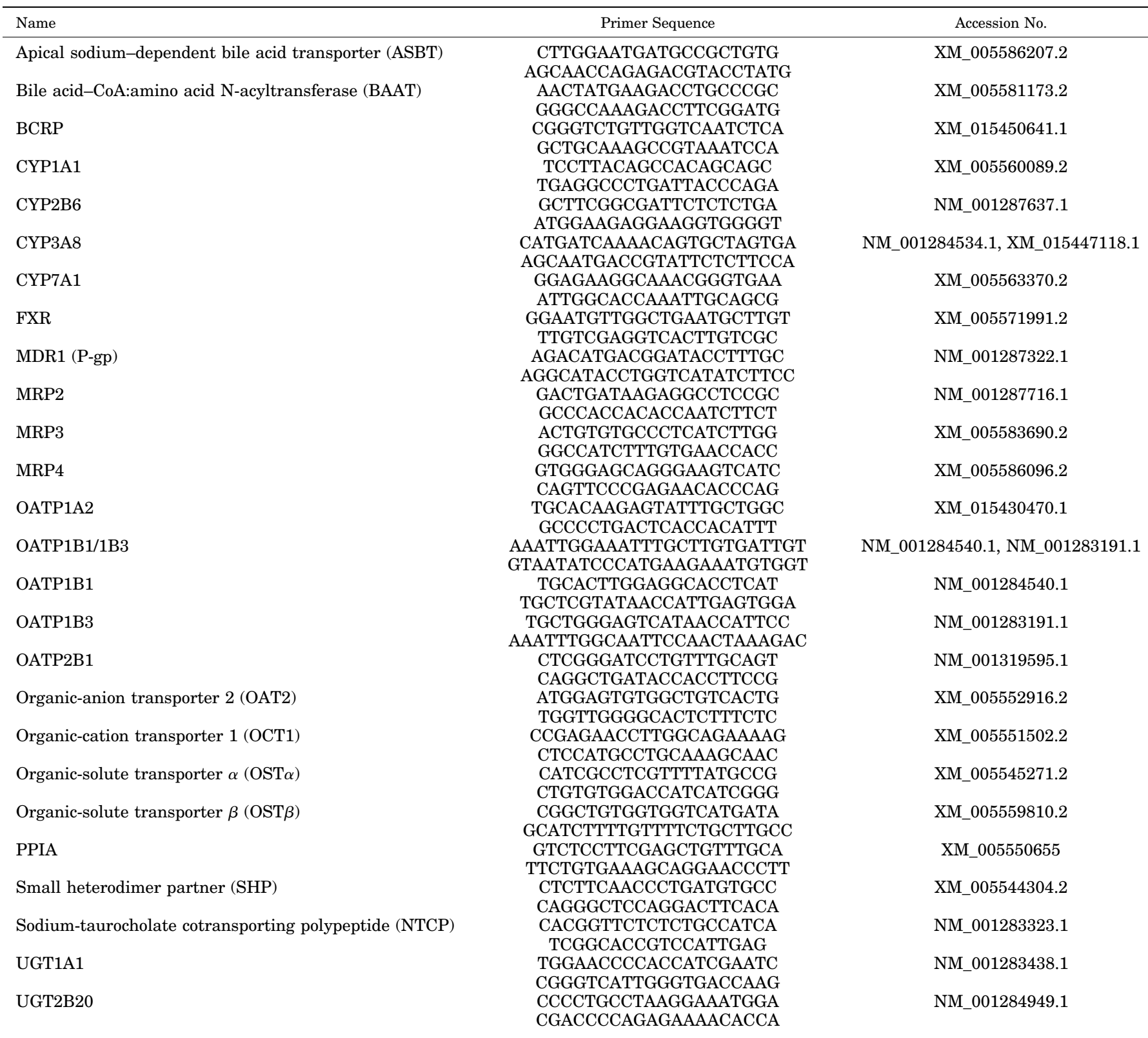

No., number.

Then the mixture samples were subject to protein precipitation using $100 \mu \mathrm{l}$ of $6 \mathrm{M}$ formic acid containing the internal standard mixture of ${ }^{15} \mathrm{~N}_{4}$-CPI (20 nM), $\mathrm{d}_{8}$-CPIII (50 nM), and $\mathrm{d}_{3}$-RIF (200 nM). After the plates were vortexed for 5 minutes, the total sample was transferred into a Biotage Isolute SLE+ 96-well plate. Three 500- $\mu$ l ethyl acetate (total $1.5 \mathrm{ml}$ ) aliquots were added to each well and allowed to elute under gravity. After samples were evaporated to dryness under a nitrogen stream, they were reconstituted with $60 \mu \mathrm{l}$ of acetonitrile/ $1 \mathrm{M}$ formic acid $(20: 80, \mathrm{v} / \mathrm{v})$. A $20-\mu \mathrm{l}$ aliquot was injected for analysis by LC-MS/MS.

The bioanalysis was performed using a Triple Quad 6500 mass spectrometer (SCIEX, Foster City, CA) coupled to a Ultra-HPLC LC-30AD pump and a SIL-30ACMP autosampler (Shimadzu, Kyoto, Japan). Chromatographic separation was accomplished using an Acquity UPLC BEH C18 column $(2.1 \times 150 \mathrm{~mm}, 1.8 \mu \mathrm{m})$ with a VanGuard BEH C18 column $(2.1 \times 10 \mathrm{~mm}, 1.7 \mu \mathrm{m})$ (Waters,
Milford, MA). The system was maintained at $60^{\circ} \mathrm{C}$. The mobile phase consisted of two solvents: solvent A ( $0.1 \%$ formic acid) and solvent B ( $0.1 \%$ formic acid in acetonitrile). The total run time was 7.5 minutes with total flow rate of $0.5 \mathrm{ml} / \mathrm{min}$. The gradient was started at $35 \% \mathrm{~B}$, and this was followed by a linear increase to $40 \% \mathrm{~B}$ in 3.6 minutes, ramp to $95 \% \mathrm{~B}$ in 0.15 minutes, maintaining 95\% B for 1.35 minutes, and then a linear decrease to $35 \%$ in 0.2 minutes. The column was equilibrated at $35 \% \mathrm{~B}$ for 2.2 minutes before the next injection. The electrospray ionization source was used in the positive ion mode. The LC-MS/MS detector was operated at unit resolution in the multiple reaction monitoring mode using the transitions of the protonated forms of CPI, CPIII, and RIF at $\mathrm{m} / \mathrm{z}$ $655.4>596.3,{ }^{15} \mathrm{~N}_{4}$-CPI at $\mathrm{m} / \mathrm{z} 659.3>600.3, \mathrm{~d}_{8}$-CPIII at $\mathrm{m} / \mathrm{z}$ $663.3>602.3, \mathrm{RIF}$ at $\mathrm{m} / \mathrm{z} 823.1>791.2$, and $\mathrm{d}_{3}-\mathrm{RIF}$ at $\mathrm{m} / \mathrm{z} 826.1>794.2$. Optimized parameters were as follows: curtain gas, gas 1, and gas 2 (nitrogen) at 30,75 , and $60 \mathrm{U}$, respectively; source temperature 
$450^{\circ} \mathrm{C}$; and Ion Spray voltage $4000 \mathrm{~V}$. The system control and data processing were performed on the Analyst v1.6.2 software.

\section{Quantification of $4 \beta \mathrm{HC}$ and Cholesterol in Plasma by LC-MS/MS}

The bioanalytical analyses of $4 \beta \mathrm{HC}$ and cholesterol were performed as described in detail by Goodenough et al. (2011). This assay provided the measurement of $4 \beta \mathrm{HC}$ in plasma with a lower limit of quantification established at 5.0 nM. The intraday and interday accuracy for the measurements was within $6 \%$ of nominal concentrations, and the precision for the assay was less than $5 \%$ relative S.D. The changes of the measured concentrations at both the 1- and 4-month time points were within $15 \%$ of that at time 0 (Goodenough et al., 2011).

The LC-MS/MS analysis was conducted on a Triple Quad 4000 (AB Sciex) coupled with a Waters Acquity Ultra-HPLC system. The chromatographic separation was performed on an Acquity UPLC HSS T3 column $(2.1 \times 100 \mathrm{~mm}, 1.8 \mu \mathrm{m})$ from Waters using mobile phases of $0.1 \%$ formic acid in water and methanol. The flow rate was $0.5 \mathrm{ml} / \mathrm{min}$, and total run time was 15 minutes. The LC column was maintained at $30^{\circ} \mathrm{C}$. The analyte was monitored using selected reaction monitoring in positive ion electrospray mode with the optimized collision gas, curtain gas, ion source gas 1 , and gas 2 set at 5, 30, 25 and 40, respectively. The ion spray voltage was set at $5500 \mathrm{~V}$, and source temperature was set at $450^{\circ} \mathrm{C}$; declustering potential and collision energy were optimized to be $20 \mathrm{~V}$ and $20 \mathrm{eV}$. Quantitation was performed using the transitions of $\mathrm{m} / z 613.5>490.5(4 \beta \mathrm{HC}), \mathrm{m} / z$ $620.5>497.5\left(\mathrm{~d}_{7}-4 \beta \mathrm{HC}\right), \mathrm{m} / z 492.5>369.5$ (cholesterol), and $m / z$ $499.5>376.5\left(\mathrm{~d}_{7}\right.$-cholesterol). The system control and data processing were performed on the Analyst v1.5.1 software.

\section{Quantification of Transporter and Enzyme Gene Expression by Quantitative Reverse-Transcription Polymerase Chain Reaction}

Total RNA was extracted from monkey liver, proximal jejunum, and kidney samples using the RNeasy Mini kit according to the manufacturer's instructions (Qiagen, Valencia, CA). Genomic DNA was digested by on-column DNase treatment (Qiagen). The concentrations and purity of RNA samples were assessed spectrophotometrically at $260 \mathrm{~nm}$ using the Nanodrop 8000 instrument (NanoDrop Technologies, Wilmington, DE). cDNA was synthesized using SuperScript IV Reverse Transcriptase (Thermo Fisher Scientific, Belmont, CA).

The expression of transporter and enzyme genes and that of the housekeeping gene encoding peptidylprolyl isomerase A (PPIA) were analyzed by quantitative PCR with a ViiA 7 Real-Time PCR System (Life Technologies, Grand Island, NY) using SYBR Green fluorescence detection. The PCR reactions were started at $95^{\circ} \mathrm{C}$ for 10 minutes and were followed by 40 amplification cycles of 15 seconds at $95^{\circ} \mathrm{C}$ and 1 minute at $60^{\circ} \mathrm{C}$. Primer sequences are shown in Table 1.

Gene expression was evaluated using the cycling threshold value (Ct) for each sample. Expression of the target genes was normalized to that of PPIA gene since the expression of the latter gene was not influenced by RIF. The variable $\Delta \mathrm{Ct}$ was calculated by subtracting a $\mathrm{Ct}$ value of target transcript from that of PPIA, and the comparative variable $\Delta \Delta \mathrm{Ct}$ is the difference of $\Delta \mathrm{Ct}$ between the RIF and vehicle control groups. Gene expression is expressed as a fold change of mRNA amount in sample relative to the vehicle control calculated using the $2^{-\Delta \Delta \mathrm{Ct}}$ method.

\section{Pharmacokinetic Analyses}

The $C_{\max }$ and $A U C$ from time 0 to 24 hours $\left(A U C_{0-24 \mathrm{~h}}\right)$ of RIF, CPI, and CPIII were obtained from plasma concentrations versus time data by performing a noncompartmental analysis with mixed log-linear trapezoidal method. The terminal elimination rate constant of RIF was determined by nonlinear regression analysis of the terminal segment of the plasma concentration-time curve. These pharmacokinetic parameters were derived using validated software Phoenix WinNonlin, version 8.1 (Certara, Princeton, NJ).

\section{Statistical Analyses}

The results are expressed as mean \pm S.D. in the text and tables. Statistical comparison of the $A U C_{0-24 \mathrm{~h}}, C_{\max }$, and $t_{1 / 2}$ among different days (day 4, day 8, day 15 , and day 25 ) or treatments (vehicle and RIF groups) in the monkey experiments was done by one-way ANOVA. When the $F$ value showed that there were significant differences among days and treatments, the Dunnett's multiple comparisons test was used to determine which day and treatment differed. The statistical analysis of tissue gene expression was performed using paired $t$ test. All data were analyzed with the GraphPad Prism Statistical Package (GraphPad Software, San Diego, CA). Differences were considered significant for $P<0.05$.

\section{Results}

\section{Effects of Administration of RIF on Plasma Levels of $4 \beta \mathrm{HC}$, CPI, and CPIII}

The plasma concentrations of $4 \beta \mathrm{HC}, \mathrm{CPI}$, and CPIII for the cynomolgus monkeys treated with $15 \mathrm{mg} / \mathrm{kg}$ per day of RIF are shown in Figs. 2 and 3. The RIF treatment was started on day 8 and terminated on day 19 and day 14 in experiments 1 and 2 , respectively (Fig. 1). The plasma concentrations of $4 \beta \mathrm{HC}$, CPI, and CPIII were determined 1 week before, during the RIF treatment, and 1 week thereafter (experiment 1 only) for all monkeys. The average plasma concentration of $4 \beta \mathrm{HC}$ in the baseline period of experiment 1 was $108 \pm 24 \mathrm{ng} / \mathrm{ml}$ on day $1,109 \pm 52 \mathrm{ng} / \mathrm{ml}$ on day 2 , and $123 \pm 62 \mathrm{ng} / \mathrm{ml}$ on day 3 (Fig. 1A). The plasma $4 \beta \mathrm{HC}$-to-cholesterol concentration ratio in the study remained unchanged during the first 7 -day period. However, there was a steady rise in the predose $4 \beta \mathrm{HC}$ plasma levels during the RIF treatment period from $114 \pm 47 \mathrm{ng} / \mathrm{ml}$ on day 9 to $357 \pm 160 \mathrm{ng} / \mathrm{ml}$ on day 20 (Fig. $1 \mathrm{~A}$ ). The concentration continued to increase for 2 days after RIF cessation, reaching a maximum concentration of $445 \pm 194 \mathrm{ng} / \mathrm{ml}$ on day 22 (3.9-fold increase). RIF produced a similar increase in the ratio of $4 \beta \mathrm{HC}$ to cholesterol in monkeys. The concentration and ratio declined slowly after day 22 to approximately 20\%-30\% within 3 days (Fig. 1A), a finding consistent with the literature (Kasichayanula et al., 2014; Li et al., 2014).

Temporal variations of $\mathrm{CP}$ (trend analysis) were also assessed using data generated from the same daily samples in experiment 1. Although CP varied, irrespective of RIF dosing, there was no clear trend of plasma CPI and CPIII levels over the 26 days, indicating no major effect of RIF on CPI and CPIII (Fig. 2, B and C). Similarly, in a separate experiment (experiment 2), plasma CPI and CPIII concentrations remained unchanged after 7 days of RIF administration compared with the baseline and vehicle controls (Fig. 3, A and B).

There was a dramatic change in RIF trough concentration after administration of RIF itself, with 47 - and 22 -fold decreases when repeatedly administered once a day for 12 and 7 days in experiments 1 and 2, respectively, as compared with the first dose (Fig. 2D; Fig. 3C), indicating that RIF induced its own metabolism. The RIF $A U C_{0-24 \mathrm{~h}}$, $C_{\max }$, and $T_{1 / 2}$ after single and multiple RIF administration in experiment 1 are shown in Fig. $1 \mathrm{E}$ and Table 2. Taking multiple doses of $15 \mathrm{mg} / \mathrm{kg}$ RIF decreased the mean $A U C_{0-24 \mathrm{~h}}$ and $C_{\max }$ of RIF by $94 \%$ and $86 \%$, respectively, compared with a single dose of $15 \mathrm{mg} / \mathrm{kg}$ RIF (day $15 \mathrm{vs}$. day 8: $5.2 \pm 3.8 \mathrm{vs.}$ 

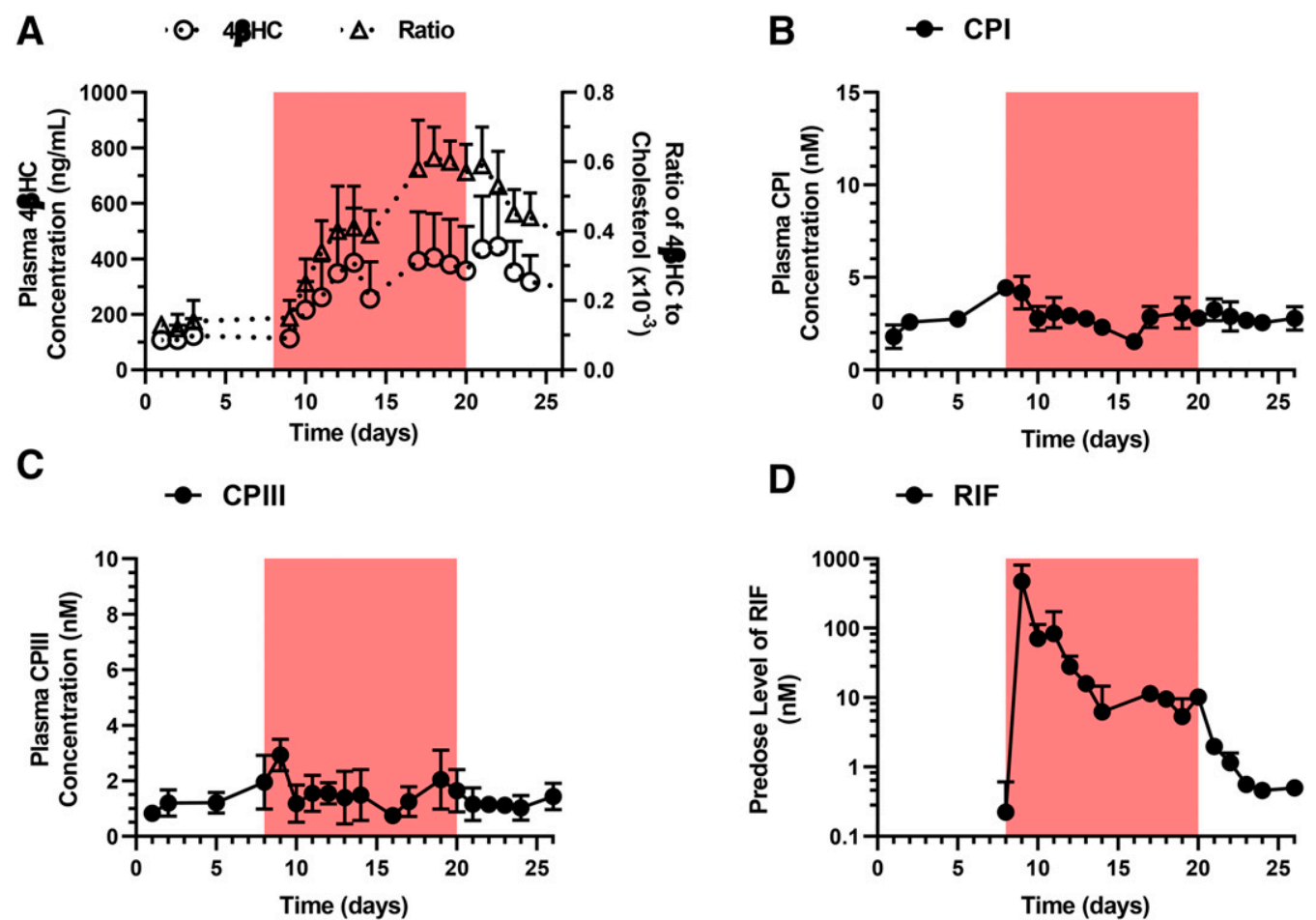

Fig. 2. Mean plasma concentrations of $4 \beta \mathrm{HC}$ and ratios of $4 \beta \mathrm{HC}$ to cholesterol (A), CPI (B and F), CPIII (C and G), and RIF (D and E) before (day 1 to day 7), during (day 8 to day 19), and after (day 20 to day 26) administration of RIF (15 mg/kg per day) in three male cynomolgus monkeys. To evaluate the effect of RIF doses on plasma concentration of RIF and CP, the plasma concentration-time profiles of RIF (E), CPI (F), and CPIII (G) on day 4 (before dose; blue circles), day 8 and day 15 (after the first and eighth RIF doses, respectively; red squares), and day 25 (6 days after the last RIF dose; green triangles) are shown as the mean and S.D. Pharmacokinetics are summarized in Table 2.

$84.2 \pm 46.9 \mu \mathrm{M} \bullet$ hour and $1213 \pm 630$ vs. $8573 \pm 4720 \mathrm{nM}$, respectively). In addition, the multiple RIF doses reduced the mean $t_{1 / 2}$ by $57 \%$ as compared with the single RIF dose $(2.1 \pm 0.49$ vs. $4.9 \pm 0.59$ hours) (Table 2$)$, confirming enhanced clearance of RIF after repeated dosing. In agreement, in experiment 2 , the decrease was $48 \%$ for RIF $A U C_{0-6} \mathrm{~h}$ and $51 \%$ for RIF $C_{\max }$ (Fig. 3D; Table 3) (day 14 vs. day $8: 36.8 \pm 30.1$ vs. $71.4 \pm 6.2 \mu \mathrm{M} \bullet$ hour and $8.2 \pm 6.0$ vs. $16.9 \pm 0.8 \mu \mathrm{M}$, respectively).

The effect of single versus multiple doses of oral RIF on plasma CPI and CPIII concentrations in a single day is further illustrated in Figs. 2, F and G and 3, E and F. As shown, both single- and multiple-dose RIF administration increased the plasma CP levels compared with the baseline or vehicle control, suggesting OATP1B inhibition. However, CPI and CPIII plasma levels increased to different extents, as the magnitude of the CPI or CPIII plasma increase was higher after a single administration compared with multiple RIF administration (Tables 2 and 3). One exception is the plasma CPIII levels in experiment 2. The comparison is difficult in experiment 2 because of the incomplete examination of $\mathrm{CP}$ systemic exposure (1-, 2-, 4-, and 6-hour samples per collecting period per monkey). As summarized in Table 2, a single dose of RIF on day 8 in experiment 1 significantly increased the $A U C_{0-24 \mathrm{~h}}$ of CPI and CPIII by 4.4- and 5-1-fold, respectively, as compared with the baseline control on day 4 (182.5 $\pm 35.1 \mathrm{vs}$. $41.9 \pm 7.6 \mathrm{nM} \bullet$ hour and $100.7 \pm 44.5$ vs. $19.6 \pm 9.7 \mathrm{nM} \bullet$ hour, respectively) $(P<0.05)$, whereas multiple RIF dosing resulted in only 1.6- and 2.1-fold increases of CPI and CPIII $A U C_{0-24} \mathrm{~h}$, respectively $(65.6 \pm 13.8$ vs. $41.9 \pm 7.6 \mathrm{nM} \bullet$ hour and $41.9 \pm 17.3$ vs. $19.6 \pm 9.7 \mathrm{nM} \bullet$ hour, respectively). Termination of RIF treatment resulted in a significant decrease in CP $A U C_{0-24 \mathrm{~h}}$. Six days after termination (day 25), the average $A U C_{0-24 \mathrm{~h}}$ of CPI and CPIII had returned to the pretreatment values $(46.1 \pm 10.4$ vs. $41.9 \pm 7.6 \mathrm{nM} \bullet$ hour and $22.5 \pm 10.6$ vs. $19.6 \pm 9.7 \mathrm{nM} \bullet$ hour, respectively). We have recently reported that there were 2.6- and 3.6-fold increases of CPI and CPIII $A U C_{0-24} \mathrm{~h}$, respectively, after a single dose of $15 \mathrm{mg} / \mathrm{kg}$ RIF (Shen et al., 2016). In experiment 2, multiple $\mathrm{RIF}$ doses resulted in a decrease in the mean CPI $A U C_{0-6 \mathrm{~h}}$ compared with the administration of a single RIF dose, whereas there was no impact of single versus multiple RIF doses on CPIII $A U C_{0-6 \mathrm{~h}}(27.7 \pm 21.5$ vs. $41.5 \pm 8.6 \mathrm{nM} \bullet$ hour and $19.9 \pm 17.3$ vs. $18.7 \pm 2.5 \mathrm{nM} \bullet$ hour, respectively) (Table 3). However, in experiment 2, sparse plasma samples were collected at days 1,8 , and 14 (1-, 2-, 4-, and 6-hour samples per collecting period per monkey) for measurement. Both single and multiple RIF doses increased the CPI and CPIII $A U C_{0-6 \mathrm{~h}}$ compared with vehicle controls in experiment 2, which were 13.2 to 16.0 and $2.2-2.5 \mathrm{nM}$ •hour for CPI and CPIII $A U C_{0-6}$ h, respectively.

\section{Effects of RIF on OATP1B1 Gene Expression in the Liver, Small Intestine, and Kidney}

In the liver, the gene expression of OATP1B1/1B3, OATP1B1, and OATP1B3 with and without RIF was very similar and close to one after 7 days of RIF treatment in three female cynomolgus monkeys $(1.1 \pm 0.25,0.85 \pm 0.16$, and $1.3 \pm 0.29$, respectively) $(P>0.05)$, suggesting that RIF had no or minimal effect on the transcripts of OATP1B in the liver (Fig. 4A; Table 4). Similarly, no induction of 

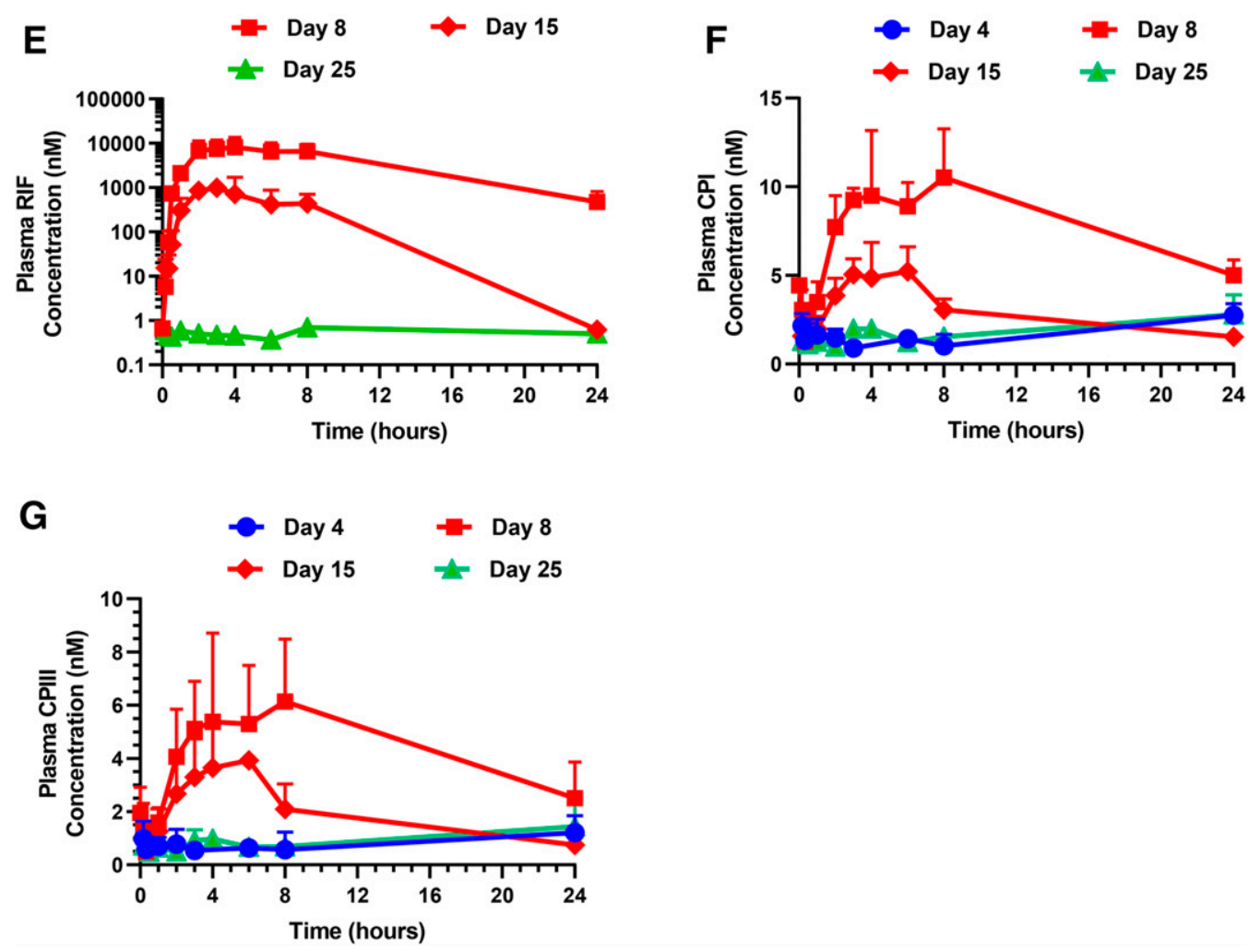

Fig. 2. Continued.

OATP1B expression was observed in the proximal jejunum after administration of $15 \mathrm{mg} / \mathrm{kg}$ orally for 7 days (Fig. 4B). Despite negligible OATP2B1 mRNA expression in the liver and kidney tissues, the expression of OATP2B1 was observed in the small intestine, and its expression was increased 3.1 \pm 1.9 -fold by RIF. However, this difference was not statistically significant because of large interindividual variability $(P=0.131)$ (Table 4). In contrast, a significant increase of CYP3A8 expression by $5.0 \pm 1.1-$ and $3.7 \pm 1.2-$ fold was observed in the liver and small intestine, respectively, after multiple doses RIF administration $(P<0.05)$ (Fig. $4, \mathrm{~A}$ and B). Similar increases of CYP2B6, UGT1A1, and UGT2B20 were observed in the liver and small intestine (2.1-4.8-fold), but not all differences have been found to be significant at $P<0.05$.

Minimal or no MRP4 mRNA expression was detected in control liver tissue. The expressions of MRP3 and breast cancer resistance protein (BCRP) in the liver were not modulated by RIF (Fig. 4A). Reverse-transcription PCR showed approximately 2-fold induction of the expressions of MDR1 (P-gp) and MRP2 in the liver by RIF. Conversely, MDR1, MRP2, MRP3, MRP4, and BCRP mRNA expressions were induced in the small intestine (proximal jejunum) by RIF (1.8-3.3-fold) (Fig. 4C; Table 4).

A significant but slight increase of UGT2B20 mRNA expression by $1.6 \pm 0.30$ was observed in the kidney after multiple RIF doses $(P<0.05)$ (Fig. 4B). The other significantly increased gene expression in the kidney tissue was the transporter OAT2 $(4.4 \pm 1.5 ; P=0.026)$.

\section{Discussion}

The present study describes absence of OATP1B1 and OATP1B3 induction mediated by RIF. Multiple administration of the PXR activator has a substantial effect on the activity and expression of monkey CYP3A in vivo, whereas the effects on monkey OATP1B activity and gene expression are less pronounced after multiple administration.

$4 \beta \mathrm{HC}$ and $\mathrm{CP}$ are among the most well-established endogenous biomarkers of CYP3A and OATP1B, respectively (Diczfalusy et al., 2011; Kasichayanula et al., 2014; Li et al., 2014; Shen et al., 2016; Tahara et al., 2019; Takehara et al., 2019; Gu et al., 2020). Therefore, $4 \beta \mathrm{HC}, \mathrm{CPI}$, and CPIII were selected as in vivo probes of CYP3A and OATP1B activities, and we studied the day-to-day change from predose plasma levels and throughout the entire study with the strong PXR activator RIF. The evaluation of endogenous biomarker involves a unique three-phase crossover design (Fig. 1A). The three periods are 1) baseline, 2) RIF treatment, and 3 ) washout periods. The first period is necessary to characterize any acute and chronic effects of RIF on circulating $4 \beta \mathrm{HC}, \mathrm{CPI}$, and CPIII levels. RIF administration resulted in a rapid increase in the predose plasma $4 \beta \mathrm{HC}$ concentration and $4 \beta \mathrm{HC}$-to-cholesterol ratio during the RIF treatment period compared with the baseline control (Fig. 2A), analogous to what has been observed previously in monkeys and humans (Diczfalusy et al., 2011; Kasichayanula et al., 2014; Li et al., 2014). In contrast, the predose CPI and CPIII concentrations during the RIF treatment period were not influenced, as illustrated in two separate experiments in Figs. 2, B and C and 3, A and B. Hence, it is unlikely that OATP1B1 and OATP1B3 are induced by RIF. To our knowledge, this is the first report of the trend analysis of plasma CPI and CPIII concentrations from daily samples that are collected prior to, during, and after RIF administration, although CP has been suggested as a putative endogenous marker of OATP1B activity. Kunze et al. (2018) 

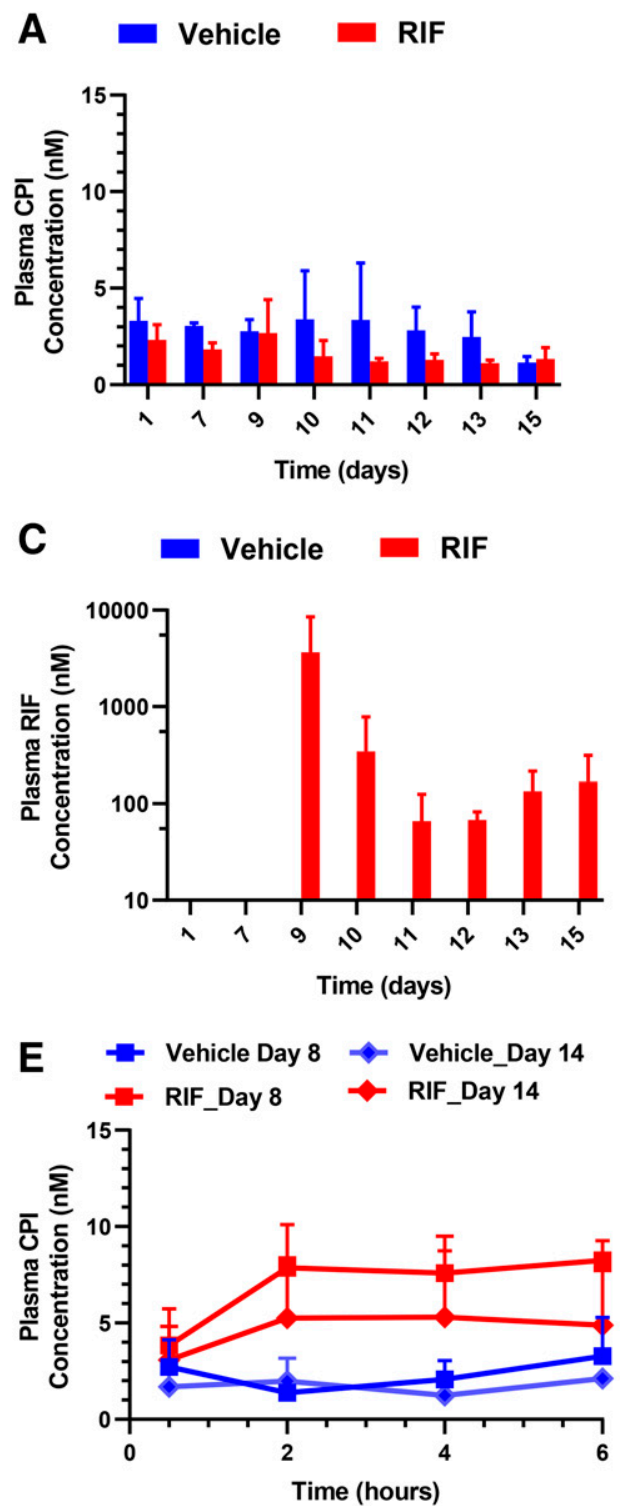

B
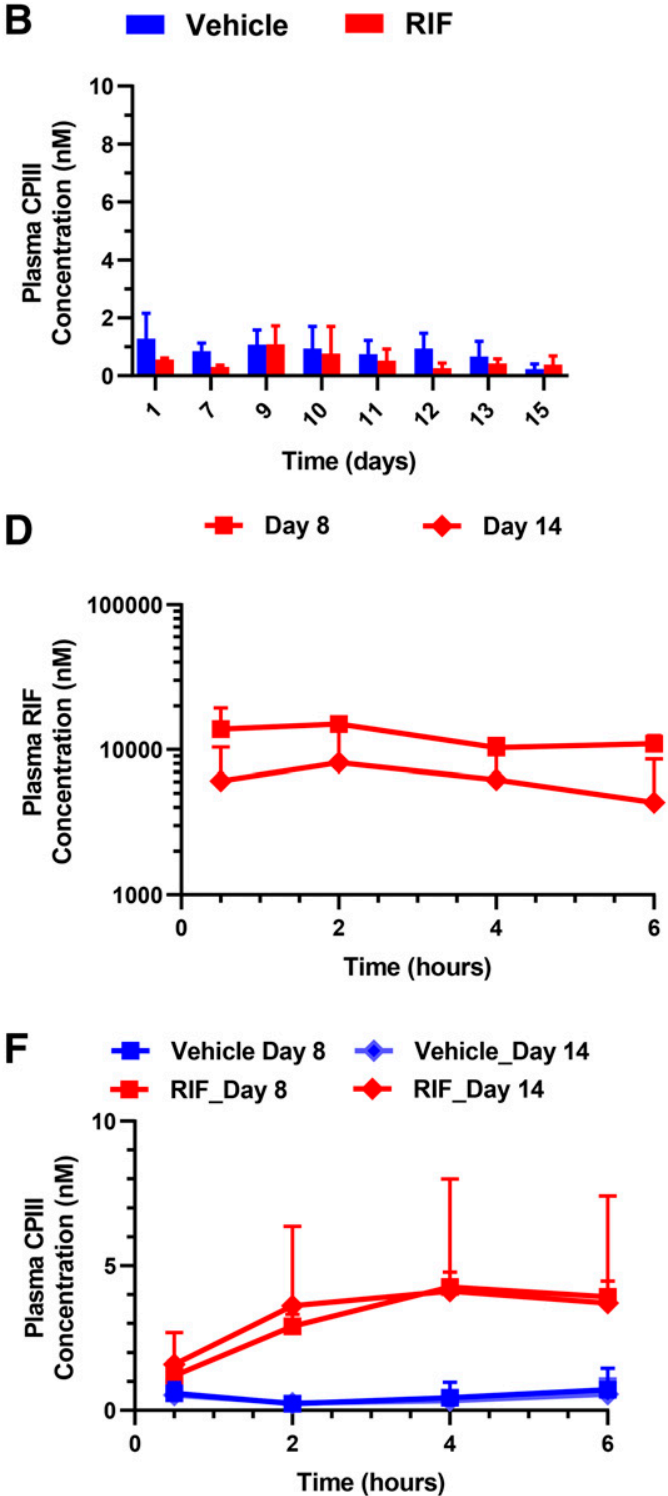

Fig. 3. Mean plasma concentrations of CPI (A and E), CPIII (B and F), and RIF (C and D) before (day 1 to day 7 ), during (day 8 to day 14), and after (day 15) administration of vehicle or RIF (15 mg/kg per day) in three female cynomolgus monkeys ( $n=3$ per group). To evaluate the effect of RIF doses on plasma concentration of RIF and CP, the plasma concentration-time profiles of RIF (D), CPI (E), and CPIII (F) on day 8 [after the first vehicle (blue squares) or RIF dose (red squares)] and day 14 [after the seventh vehicle (blue diamonds) or RIF dose (red diamonds)] are shown as the mean and S.D. values. Pharmacokinetics are summarized in Table 3.

investigated the effect of $600 \mathrm{mg}$ single or multiple RIF dose on the plasma concentrations of $\mathrm{CP}$ in 12 healthy volunteers (Kunze et al., 2018). The authors reported that the CPI and CPIII concentrations in the plasma samples collected prior to the first RIF administration (i.e., at 0 hours) were similar to those from the plasma samples that were taken immediately before administration of the sixth RIF dose and 20-24 hours after administration of the fifth RIF dose. Therefore, the predose plasma CP profile in this study is consistent with that in humans.

To further verify whether and to what extent RIF inducer has an effect on the expression of OATP1B1 and OATP1B3, we subsequently carried out a gene transcription-profiling analysis in the liver, small intestine, and kidney from monkeys after 7 days of oral administration of vehicle or $15 \mathrm{mg} / \mathrm{kg}$ RIF (Fig. 1B). Our data revealed increased mRNA expression of
CYP3A8 (5.0- and 3.7-fold), CYP2B6 (4.7- and 4.8-fold), and UGT1A1 (4.1- and 2.8-fold) in the liver and small intestine (Fig. 4, A and B; Table 4). This is consistent with the previous observations in monkeys and humans, in which CYP3A (Backman et al., 1996; Kim et al., 2010), CYP2B6 (Goodwin et al., 2001; Loboz et al., 2006), and UGT1A1 (Chattopadhyay et al., 2018) were inducible by RIF through a PXR-dependent mechanism (Niemi et al., 2003; Sinz et al., 2008; Chu et al., 2009). Similarly, it has been reported that repeated RIF dosing increased human CYP3A protein levels in the liver and gut by 2.2-4.7 fold (Combalbert et al., 1989; Greiner et al., 1999; Glaeser et al., 2005). In contrast, the induction of OATP1B1 and OATP1B3 mRNA expression in the liver was absent with $1.1 \pm 0.25-, 0.85 \pm 0.16-$, and $1.3 \pm 0.29-$ fold changes for the transcripts of OATP1B1/1B3, OATP1B1, and OATP1B3, respectively $(P>0.05)$ (Fig. 4A; Table 4). 
TABLE 2

Pharmacokinetics of RIF, CPI, and CPIII before, during, and after multiple administration of RIF (15 mg/kg) to cynomolgus monkeys in experiment 1 Data represent the mean and S.D. from three monkeys. Statistics were conducted by paired $t$ test method for RIF pharmacokinetic parameters comparison. Statistics were conducted by one-way ANOVA followed by Dunnett's multiple comparison method for CPI and CPIII pharmacokinetic parameter comparison.

\begin{tabular}{|c|c|c|c|c|c|}
\hline \multirow[b]{2}{*}{ Analyte } & \multirow[b]{2}{*}{ Exposure } & \multirow[b]{2}{*}{ Before RIF Treatment (Day 4) } & \multicolumn{2}{|c|}{ During RIF Treatment } & \multirow[b]{2}{*}{$\begin{array}{l}\text { After RIF Treatment ( } 8 \text { Days after } \\
\text { the Last RIF Dosing) (Day 25) }\end{array}$} \\
\hline & & & $\begin{array}{l}\text { The First RIF } \\
\text { Dosing (Day 8) }\end{array}$ & $\begin{array}{l}\text { The Eighth RIF } \\
\text { Dosing (Day 15) }\end{array}$ & \\
\hline \multirow[t]{3}{*}{ RIF } & $A U C_{0-24 \mathrm{~h}}(\mu \mathrm{M} \bullet \mathrm{h})$ & NA & $84.2 \pm 46.9$ & $5.2 \pm 3.8^{\mathrm{a}}$ & $0.013 \pm 0.002$ \\
\hline & $C_{\max }(\mathrm{nM})$ & NA & $8573 \pm 4720$ & $1213 \pm 630^{\mathrm{a}}$ & $0.81 \pm 0.14$ \\
\hline & $t_{1 / 2}(\mathrm{~h})$ & NA & $4.9 \pm 0.59$ & $2.1 \pm 0.49^{\mathrm{a}}$ & \\
\hline \multirow[t]{2}{*}{ CPI } & $A U C_{0-24 \mathrm{~h}}(\mathrm{nM} \bullet \mathrm{h})$ & $41.9 \pm 7.6$ & $182.5 \pm 35.1^{* * *}$ & $65.6 \pm 13.8$ & $46.1 \pm 10.4$ \\
\hline & $C_{\max }(\mathrm{nM})$ & $2.8 \pm 0.7$ & $11.4 \pm 2.5^{* * *}$ & $5.4 \pm 1.1$ & $2.9 \pm 1.0$ \\
\hline \multirow[t]{2}{*}{ CPIII } & $A U C_{0-24 \mathrm{~h}}(\mathrm{nM} \bullet \mathrm{h})$ & $19.6 \pm 9.7$ & $100.7 \pm 44.5^{*}$ & $41.9 \pm 17.3$ & $22.5 \pm 10.6$ \\
\hline & $C_{\max }(\mathrm{nM})$ & $1.2 \pm 0.6$ & $6.4 \pm 2.7^{*}$ & $3.8 \pm 1.6$ & $1.5 \pm 0.8$ \\
\hline
\end{tabular}

NA, not applicable.

${ }^{a} P<0.05$ compared with the single RIF dose (Day 8).

${ }^{*} P<0.05 ; * * * P<0.001$ compared with the predose control (Day 4 ).

We detected very low or negligible OATP2B1 expression in monkey livers and kidneys. However, it was expressed in the small intestine and was inducible by RIF, although the increase was not statistically significant $(3.1 \pm 1.9$-fold $)$ $(P>0.05)$, suggesting that PXR may be involved in the regulation of intestinal OATP expression (Fig. 4B; Table 4). Differential induction of intestinal and hepatic CYP enzymes by RIF have been observed previously (Fromm et al., 1996). Although it might be appropriate to note that addition of transporter protein expression data could further validate the observation, the methodologies used in this study are sufficient to support the conclusions. First, mRNA expression analysis is considered the gold standard for drugmetabolizing enzyme and transporter induction studies. Generally, mRNA expression data are correlated well with protein expression data. Second, the activities of CYP3A and OATP1B monitored by plasma endogenous biomarker levels are in agreement with the mRNA expressions in cynomolgus monkeys. Although the predose plasma $4 \beta \mathrm{HC}$ concentrations and CYP3A8 gene expressions are significantly increased by multiple doses of RIF in monkeys, the baseline CP levels and OATP1B gene expressions are not affected by the treatment. Remarkably, despite the contradictory reports on OATP1B induction by PXR activators in human hepatocytes and liver biopsies, there are no data that exist regarding the PXR-binding motifs in the promoter regions of OATP1B1 and OATP1B3. Rat hepatic transporter Oatp1a4 expression was induced by pregnenolone-16 $\alpha$ carbonitrile through four PXR response elements located in the rat Oatp1a4 promoter (Guo et al., 2002). A PXR response element was identified in the promoter of the human OATP1A2 gene, and its direct interaction with PXR was demonstrated using chromatin immunoprecipitation and PXR antagonist A-792611 (Meyer zu Schwabedissen et al., 2008). Interestingly, Meyer Zu Schwabedissen et al. (2010) also identified two functional farnesoid X receptor (FXR) response elements and one liver X receptor (LXR) response element in human OATP1B1 promoter region using detailed promoter analysis. In addition, the direct interaction between the identified response elements with FXR and LXR was confirmed using chromatin immunoprecipitation method. Moreover, LXR or FXR agonists but not PXR or constitutive androstane receptor agonists displayed OATP1B1 induction potential using isolated primary human hepatocytes (Meyer Zu Schwabedissen et al., 2010). Taken together, these data clearly indicate that the activities and expressions of hepatic OATP1B1 and OATP1B3 transporter are not induced by multiple RIF doses in monkeys.

The lack of inducing effect of RIF on OATP1B1 and OATP1B3 gene expression has, to our knowledge, not been previously reported. If this inductive effect of RIF is also

TABLE 3

Systemic exposures of RIF, CPI, and CPIII during and after multiple administration of RIF ( $15 \mathrm{mg} / \mathrm{kg})$ to cynomolgus monkeys in experiment 2 Data represent the mean and S.D. from three monkeys. Statistics were conducted by one-way ANOVA followed by Dunnett's multiple comparison method.

\begin{tabular}{|c|c|c|c|c|c|}
\hline \multirow{2}{*}{ Analyte } & \multirow[b]{2}{*}{ Exposure } & \multicolumn{2}{|c|}{ Vehicle Treatment } & \multicolumn{2}{|c|}{ RIF Treatment } \\
\hline & & $\begin{array}{l}\text { The First Vehicle Dosing } \\
\text { (Day 8) }\end{array}$ & $\begin{array}{l}\text { One Day after the Last Vehicle Dosing } \\
\text { (Day 14) }\end{array}$ & $\begin{array}{l}\text { The First RIF Dosing } \\
\text { (Day 8) }\end{array}$ & $\begin{array}{l}\text { One Day after the Last RIF Dosing } \\
\text { (Day 14) }\end{array}$ \\
\hline \multirow[t]{2}{*}{ RIF } & $\begin{array}{l}A U C_{0-6 \mathrm{~h}} \\
(\mu \mathrm{M} \bullet \mathrm{h})\end{array}$ & NA & NA & $71.4 \pm 6.2$ & $36.8 \pm 30.1$ \\
\hline & $C_{\max }(\mu \mathrm{M})$ & NA & NA & $16.9 \pm 0.8$ & $8.2 \pm 6.0$ \\
\hline \multirow[t]{2}{*}{ CPI } & $\begin{array}{c}A U C_{0-6} \mathrm{~h} \\
(\mathrm{nM} \bullet \mathrm{h})\end{array}$ & $13.2 \pm 2.7$ & $16.0 \pm 9.8$ & $41.5 \pm 8.6$ & $27.7 \pm 21.5$ \\
\hline & $C_{\max }(\mathrm{nM})$ & $4.3 \pm 1.3$ & $8.5 \pm 6.7$ & $8.6 \pm 1.2$ & $6.1 \pm 4.9$ \\
\hline \multirow[t]{2}{*}{ CPIII } & $\begin{array}{l}A U C_{0-6 \mathrm{~h}} \\
\left(\mathrm{nM} \cdot \mathrm{h}^{-}\right)\end{array}$ & $2.5 \pm 1.3$ & $2.2 \pm 2.2$ & $18.7 \pm 2.5$ & $19.9 \pm 17.3$ \\
\hline & $C_{\max }(\mathrm{nM})$ & $0.9 \pm 0.6$ & $0.6 \pm 0.4$ & $4.3 \pm 0.5$ & $4.2 \pm 3.7$ \\
\hline
\end{tabular}


A

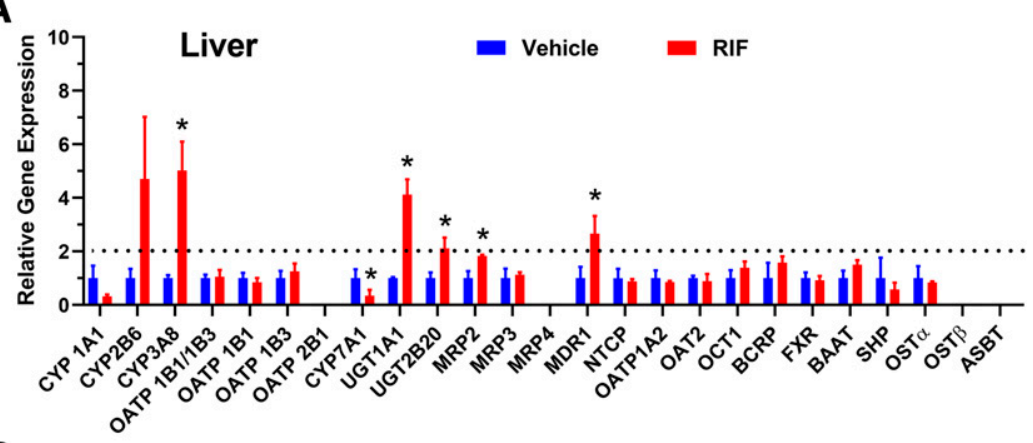

B

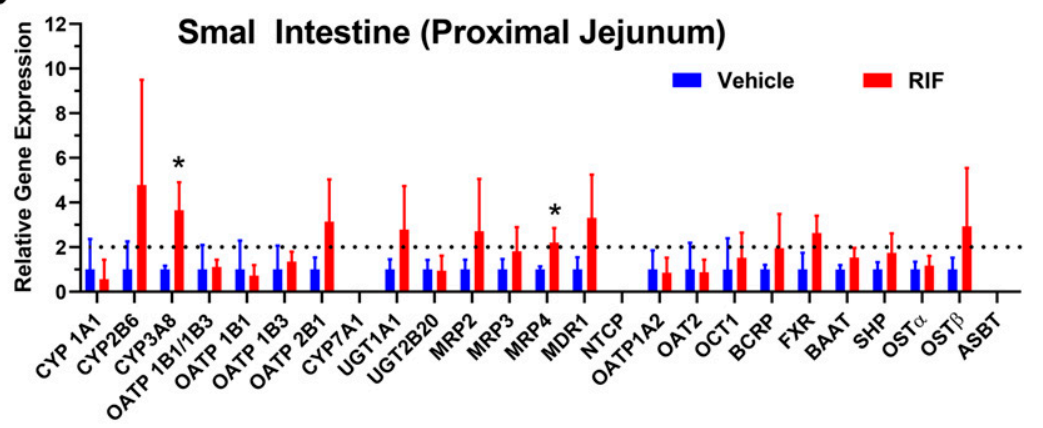

Fig. 4. Relative mRNA expression of transporters, bile acid, and bilirubin-metabolizing enzymes and nuclear receptors in the liver (A), small intestine (proximal jejunum) (B), and kidney (C) of cynomolgus monkeys treated with RIF $(15 \mathrm{mg} / \mathrm{kg}$; red bars) once daily for 7 days compared with vehicle control (blue bars). Data are expressed as mean fold-change and S.D. values from three monkeys. A line indicates a 2 -fold difference from the vehicle control. Statistics were conducted by paired $t$ test. $* P<0.05$ significantly different compared with controls. ASBT, apical sodium-dependent bile acid transporter; BAAT, bile acid-CoA:amino acid N-acyltransferase; NTCP, sodiumtaurocholate cotransporting polypeptide; OAT, organic-anion transporter; OCT1, organic-cation transporter 1; OST, organicsolute transporter; SHP, small heterodimer partner.

C

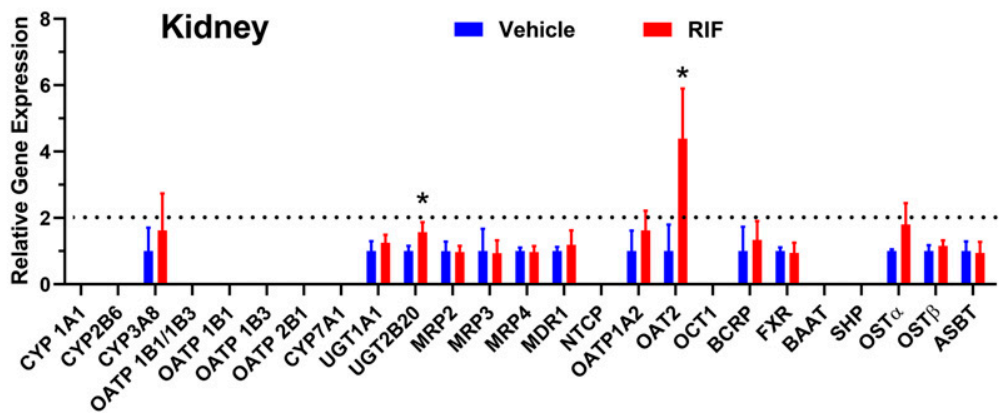

absent in humans, it would help us gain mechanistic insight for complex DDIs involving OATP1B and enzyme. In previous reports, no clear-cut induction of OATP1B with respect to activity, mRNA, or protein but an increase in OATP1B activity were assumed in the RIF-treated subjects (Lutz et al., 2018; Turk et al., 2019), raising the question of linkages between CYP3A, OATP1B, P-gp, BCRP, and MRP2 expression in humans and nonhuman primate species. By measuring the plasma RIF concentration, we have clearly shown that RIF stimulates its own clearance via induction of the metabolic enzyme (and transporter). Several lines of evidence demonstrate that RIF induces its own metabolism in monkeys. First, we showed that the RIF trough concentrations decreased steadily during the treatment, by a factor of 47 - and 22-fold in experiments 1 and 2, respectively (Fig. 2D; Fig. 3C). In addition, we demonstrated that the RIF $A U C_{0-24 \mathrm{~h}}$ (as a measure of apparent systemic clearance) and $C_{\max }$ were substantially affected by multiple RIF administration in experiment 1 (decreased by $94 \%$ and $86 \%$, respectively; Fig. 2E; Table 2) as compared with the first RIF administration. Lastly, multiple RIF administration reduced the $t_{1 / 2}$ of RIF by $57 \%$ as compared with the single-dose RIF administration. It has been reported that RIF induced its own metabolism in humans, and the systemic clearance of RIF increased by approximately 2-fold after 3 weeks of multiple RIF doses (Loos et al., 1985). Consequently, RIF administration increased CPI and CPIII plasma concentrations markedly after a single administration and, to a lesser extent, after multiple administration (Fig. 2, F and G; Fig. 3E). This decrease is likely due to the reduced portal vein concentrations of RIF, an OATP1B inhibitor, after multiple administration. Metabolism of CPI and CPIII is reported to be minor, and biliary and renal excretion are major elimination pathways of CP (Shen et al., 2016). However, caution must be taken in exclusively relating this interaction to OATP1B inhibition by RIF. In vitro studies showed that CPI and CPIII are also substrates of MRP2 (Gilibili et al., 2017; Kunze et al., 2018). The increased MRP2 expression in the liver after repeated RIF dosing (Fig. 4A) may contribute to enhanced CP clearance from the blood. Our recent study indicated that CPI was subjected to limited oral absorption with bioavailability of less than $5 \%$ in monkeys, and cyclosporin A did not significantly affect the CPI bioavailability ( $\mathrm{Gu}$ et al., 2020), suggesting that the altered intestinal MRP2 is unlikely to affect the plasma concentration of endogenous CPI. The increased MRP2 expression in the liver after repeated RIF dosing (Fig. 4A) may contribute to enhanced CP clearance from 
TABLE 4

Effects of RIF on hepatic, renal, and intestinal gene expression of transporters, bile acid, and bilirubin-metabolizing enzymes and nuclear receptors in cynomolgus monkeys

Statistics was conducted by paired $t$ test method.

\begin{tabular}{|c|c|c|c|c|c|c|}
\hline \multirow{2}{*}{ Name } & \multicolumn{2}{|l|}{ Liver } & \multicolumn{2}{|c|}{ Small Intestine (Proximal Jejunum) } & \multicolumn{2}{|l|}{ Kidney } \\
\hline & Fold Change (Mean \pm S.D.) & $P$ Value & Fold Change (Mean \pm S.D. $)$ & $P$ Value & Fold Change (Mean \pm S.D.) & $P$ Value \\
\hline CYP1A1 & $0.32 \pm 0.07$ & 0.067 & $0.57 \pm 0.87$ & 0.667 & & \\
\hline CYP2B6 & $4.7 \pm 2.3$ & 0.052 & $4.8 \pm 4.7$ & 0.251 & & \\
\hline CYP3A8 & $5.0 \pm 1.1^{*}$ & 0.003 & $3.7 \pm 1.2^{*}$ & 0.022 & $1.6 \pm 1.1$ & 0.457 \\
\hline OATP 1B1/1B3 & $1.1 \pm 0.25$ & 0.758 & $1.1 \pm 0.32$ & 0.875 & & \\
\hline OATP 1B1 & $0.85 \pm 0.16$ & 0.351 & $0.72 \pm 0.47$ & 0.743 & & \\
\hline OATP 1B3 & $1.3 \pm 0.29$ & 0.333 & $1.4 \pm 0.44$ & 0.624 & & \\
\hline OATP 2B1 & & & $3.1 \pm 1.9$ & 0.131 & & \\
\hline CYP7A1 & $0.35 \pm 0.22^{*}$ & 0.046 & & & & \\
\hline UGT1A1 & $4.1 \pm 0.56^{*}$ & 0.001 & $2.8 \pm 2.0$ & 0.199 & $1.3 \pm 0.23$ & 0.311 \\
\hline UGT2B20 & $2.1 \pm 0.40^{*}$ & 0.013 & $0.95 \pm 0.67$ & 0.913 & $1.6 \pm 0.30 *$ & 0.045 \\
\hline MRP2 & $1.8 \pm 0.05^{*}$ & 0.005 & $2.7 \pm 2.3$ & 0.281 & $0.97 \pm 0.19$ & 0.887 \\
\hline MRP3 & $1.13 \pm 0.09$ & 0.580 & $1.8 \pm 1.1$ & 0.295 & $0.94 \pm 0.39$ & 0.894 \\
\hline MRP4 & & & $2.2 \pm 0.64 *$ & 0.034 & $0.97 \pm 0.17$ & 0.830 \\
\hline MDR1 & $2.7 \pm 0.66^{*}$ & 0.021 & $3.3 \pm 1.9$ & 0.118 & $1.2 \pm 0.43$ & 0.505 \\
\hline NTCP & $0.88 \pm 0.08$ & 0.603 & & & & \\
\hline OATP1A2 & $0.85 \pm 0.04$ & 0.420 & $0.85 \pm 0.68$ & 0.824 & $1.6 \pm 0.59$ & 0.275 \\
\hline OAT2 & $0.89 \pm 0.26$ & 0.528 & $0.88 \pm 0.55$ & 0.882 & $4.4 \pm 1.5^{*}$ & 0.026 \\
\hline OCT1 & $1.4 \pm 0.24$ & 0.152 & $1.5 \pm 1.1$ & 0.638 & & \\
\hline BCRP & $1.6 \pm 0.24$ & 0.179 & $2.0 \pm 1.5$ & 0.343 & $1.3 \pm 0.57$ & 0.561 \\
\hline FXR & $0.92 \pm 0.16$ & 0.638 & $2.6 \pm 0.78$ & 0.058 & $0.94 \pm 0.31$ & 0.767 \\
\hline BAAT & $1.5 \pm 0.17$ & 0.057 & $1.5 \pm 0.43$ & 0.118 & & \\
\hline SHP & $0.58 \pm 0.25$ & 0.414 & $1.7 \pm 0.88$ & 0.240 & & \\
\hline OSTa & $0.84 \pm 0.04$ & 0.569 & $1.2 \pm 0.43$ & 0.610 & $1.8 \pm 0.64$ & 0.097 \\
\hline OSTb & & & $2.9 \pm 2.6$ & 0.277 & $1.2 \pm 0.16$ & 0.325 \\
\hline ASBT & & & & & $0.94 \pm 0.34$ & 0.836 \\
\hline
\end{tabular}

ASBT, apical sodium-dependent bile acid transporter; BAAT, bile acid-CoA:amino acid N-acyltransferase; NTCP, sodium-taurocholate cotransporting polypeptide; OAT2, organic-anion transporter; OCT1, organic-cation transporter 1; OST, organic-solute transporter; SHP, small heterodimer partner.

${ }^{*} P<0.05$ compared with the vehicle group.

the blood. Furthermore, the modulation of CP synthesis by RIF cannot completely be excluded in this study. A recent study has also shown that the magnitude of OATP1B inhibitory effect defined as $A U C_{0-24} \mathrm{~h}$ and $C_{\max }$ of CPI and CPIII was significantly higher after single RIF dose compared with multiple doses in healthy subjects (Kunze et al., 2018).

Similar findings were observed with clinical DDI studies between RIF and statins (OATP1B drug substrates) in humans. Multiple RIF doses resulted in smaller AUC and $C_{\max }$ of pitavastatin, pravastatin, and rosuvastatin compared with the single RIF dose (Kyrklund et al., 2004; Zhang et al., 2008; Lutz et al., 2018) (Livalo label: https://www.accessdata.fda.gov/ drugsatfda_docs/label/2009/022363s000lbl.pdf) (Crestor label: https://www.accessdata.fda.gov/drugsatfda_docs/label/2017/ 021366s037lbl.pdf). Because pitavastatin, pravastatin, and rosuvastatin undergo little metabolism and are substrates for P-gp, BCRP, or MRP2, the induction of these efflux transporters by RIF could decrease intestinal absorption and increase hepatic clearance of the statins, resulting in a reduced systemic exposure. Indeed, our data show that this is the case, and the exposure of monkeys to RIF for 7 days resulted in increases in P-gp and BCRP (small intestine) and MRP2 expression in the intestine and liver (Fig. 4, A and B). Moreover, the induction of its own metabolism by multiple administrations of RIF likely leads to decreased inhibition of OATP1B and reduced statin exposures as discussed above.

In summary, for the first time, the investigation of endogenous biomarker and gene expression in cynomolgus monkey studies demonstrates that OATP1B1 and OATP1B3 are not induced by multiple administration of RIF. Given the potential involvement of FXR and LXR in xenobiotic induction of OATP1B (Staudinger et al., 2013; Murray and Zhou, 2017), these results will require further evaluation to explore OATP1B induction in humans with RIF and other activators of nuclear receptors. Despite this caveat, our results demonstrate that the increased intestinal and hepatic efflux transporter expression as well as induced RIF metabolism contribute to reduced systemic exposures of CP and statins after multiple administrations of RIF. Our data also suggest that circulating CP levels have great potential as a useful tool to gain mechanistic insight of DDI involving OATP1B.

\section{Authorship Contributions}

Participated in research design: Zhang, C. Chen, Yang, Sinz, Shen. Conducted experiments: Zhang, C. Chen, S.-J. Chen, X.-Q. Chen, Shuster, Puszczalo, Fancher.

Contributed new reagents or analytic tools: Zhang, C. Chen, Shen. Performed data analysis: Zhang, C. Chen, S.-J. Chen, Shen.

Wrote or contributed to the writing of the manuscript: Zhang, C. Chen, S.-J. Chen, Sinz, Shen.

\section{References}

Backman JT, Olkkola KT, and Neuvonen PJ (1996) Rifampin drastically reduces plasma concentrations and effects of oral midazolam. Clin Pharmacol Ther 59:7-13.

Chattopadhyay N, Kanacher T, Casjens M, Frechen S, Ligges S, Zimmermann T, Rottmann A, Ploeger B, Höchel J, and Schultze-Mosgau MH (2018) CYP3A4mediated effects of rifampicin on the pharmacokinetics of vilaprisan and its UGT1A1-mediated effects on bilirubin glucuronidation in humans. $\mathrm{Br} \mathrm{J} \mathrm{Clin}$ Pharmacol 84:2857-2866.

Chu V, Einolf HJ, Evers R, Kumar G, Moore D, Ripp S, Silva J, Sinha V, Sinz M, and Skerjanec A (2009) In vitro and in vivo induction of cytochrome p450: a survey of the current practices and recommendations: a pharmaceutical research and manufacturers of America perspective. Drug Metab Dispos 37:1339-1354.

Chu X, Shih SJ, Shaw R, Hentze H, Chan GH, Owens K, Wang S, Cai X, Newton D, Castro-Perez J, et al. (2015) Evaluation of cynomolgus monkeys for the identification 
of endogenous biomarkers for hepatic transporter inhibition and as a translatable model to predict pharmacokinetic interactions with statins in humans. Drug Metab Dispos 43:851-863.

Combalbert J, Fabre I, Fabre G, Dalet I, Derancourt J, Cano JP, and Maurel P (1989) Metabolism of cyclosporin A. IV. Purification and identification of the rifampicininducible human liver cytochrome P-450 (cyclosporin A oxidase) as a product of P450IIIA gene subfamily. Drug Metab Dispos 17:197-207.

Diczfalusy U, Nylén H, Elander P, and Bertilsson L (2011) 4 $\beta$-Hydroxycholesterol, an endogenous marker of CYP3A4/5 activity in humans. $\mathrm{Br} \mathrm{J}$ Clin Pharmacol $\mathbf{7 1}$ 183-189.

Elmeliegy M, Vourvahis M, Guo C, and Wang DD (2020) Effect of P-glycoprotein (P-gp) inducers on exposure of P-gp substrates: review of clinical drug-drug in teraction studies. Clin Pharmacokinet 59:699-714.

Finch CK, Chrisman CR, Baciewicz AM, and Self TH (2002) Rifampin and rifabutin drug interactions: an update. Arch Intern Med 162:985-992.

Fromm MF, Busse D, Kroemer HK, and Eichelbaum M (1996) Differential induction of prehepatic and hepatic metabolism of verapamil by rifampin. Hepatology 24 796-801.

Gilibili RR, Chatterjee S, Bagul P, Mosure KW, Murali BV, Mariappan TT, Mandlekar S, and Lai Y (2017) Coproporphyrin-I: a fluorescent, endogenous optimal probe substrate for ABCC2 (MRP2) suitable for Vesicle-based MRP2 inhibition assay. Drug Metab Dispos 45:604-611.

Glaeser H, Drescher S, Eichelbaum M, and Fromm MF (2005) Influence of rifampicin on the expression and function of human intestinal cytochrome P450 enzymes. Br J Clin Pharmacol 59:199-206.

Goodenough AK, Onorato JM, Ouyang Z, Chang S, Rodrigues AD, Kasichayanula S, Huang SP, Turley W, Burrell R, Bifano M, et al. (2011) Quantification of 4-betahydroxycholesterol in human plasma using automated sample preparation and LC-ESI-MS/MS analysis. Chem Res Toxicol 24:1575-1585.

Goodwin B, Moore LB, Stoltz CM, McKee DD, and Kliewer SA (2001) Regulation of the human CYP2B6 gene by the nuclear pregnane X receptor. Mol Pharmacol 60 $427-431$

Greiner B, Eichelbaum M, Fritz P, Kreichgauer HP, von Richter O, Zundler J, and Kroemer HK (1999) The role of intestinal P-glycoprotein in the interaction of digoxin and rifampin. $J$ Clin Invest 104:147-153.

Gu X, Wang L, Gan J, Fancher RM, Tian Y, Hong Y, Lai Y, Sinz M, and Shen H (2020) Absorption and disposition of Coproporphyrin I (CPI) in cynomolgus monkeys and mice: pharmacokinetic evidence to support the use of CPI to inform the potential for OATP inhibition. Drug Metab Dispos 48:724-734.

Guo GL, Staudinger J, Ogura K, and Klaassen CD (2002) Induction of rat organic anion transporting polypeptide 2 by pregnenolone-16alpha-carbonitrile is via interaction with preonane X receptor. Mol Pharmacol 61:832-839.

Hagenbuch B and Stieger B (2013) The SLCO (former SLC21) superfamily of transporters. Mol Aspects Med 34:396-412.

Jones NS, Yoshida K, Salphati L, Kenny JR, Durk MR, and Chinn LW (2020) Complex DDI by fenebrutinib and the use of transporter endogenous biomarkers to elucidate the mechanism of DDI. Clin Pharmacol Ther 107:269-277.

Kandoussi H, Zeng J, Shah K, Paterson P, Santockyte R, Kadiyala P, Shen H, Shipkova P, Langish R, Burrrell R, et al. (2018) UHPLC-MS/MS bioanalysis of human plasma coproporphyrins as potential biomarkers for organic aniontransporting polypeptide-mediated drug interactions. Bioanalysis 10:633-644.

Kasichayanula S, Boulton DW, Luo WL, Rodrigues AD, Yang Z, Goodenough A, Lee M, Jemal M, and LaCreta F (2014) Validation of $4 \beta$-hydroxycholesterol and evaluation of other endogenous biomarkers for the assessment of CYP3A activity in healthy subjects. $\mathrm{Br} \mathrm{J}$ Clin Pharmacol 78:1122-1134.

Kim S, Dinchuk JE, Anthony MN, Orcutt T, Zoeckler ME, Sauer MB, Mosure KW, Vuppugalla R, Grace JE Jr., Simmermacher J, et al. (2010) Evaluation of cynomolgus monkey pregnane $\mathrm{X}$ receptor, primary hepatocyte, and in vivo pharmacokinetic changes in predicting human CYP3A4 induction. Drug Metab Dispos 38: $16-24$.

Kosa RE, Lazzaro S, Bi YA, Tierney B, Gates D, Modi S, Costales C, Rodrigues AD, Tremaine LM, and Varma MV (2018) Simultaneous assessment of transporter mediated drug-drug interactions using a probe drug cocktail in cynomolgus monkey. Drug Metab Dispos 46:1179-1189.

Kunze A, Ediage EN, Dillen L, Monshouwer M, and Snoeys J (2018) Clinical in vestigation of coproporphyrins as sensitive biomarkers to predict mild to strong OATP1B-mediated drug-drug interactions. Clin Pharmacokinet 57:1559-1570.

Kyrklund C, Backman JT, Neuvonen M, and Neuvonen PJ (2004) Effect of rifampicin on pravastatin pharmacokinetics in healthy subjects. $\mathrm{Br} J$ Clin Pharmacol 57: $181-187$.

Lai Y, Mandlekar S, Shen H, Holenarsipur VK, Langish R, Rajanna P, Murugesan S, Gaud N, Selvam S, Date O, et al. (2016) Coproporphyrins in plasma and urine can Be appropriate clinical biomarkers to recapitulate drug-drug interactions mediated by organic anion transporting polypeptide inhibition. J Pharmacol Exp Ther 358:397-404.

Li K, Zhao S, Zhang L, Wu X, Shu P, Wang Y, Feng H, Gu Z, and Han Hsu H (2014) $4 \beta$-Hydroxycholesterol as an endogenous biomarker of CYP3A activity in cynomolgus monkeys. Drug Metab Dispos 42:839-843.

Loboz KK, Gross AS, Williams KM, Liauw WS, Day RO, Blievernicht JK, Zanger UM, and McLachlan AJ (2006) Cytochrome P450 2B6 activity as measured by bupropion hydroxylation: effect of induction by rifampin and ethnicity. Clin Pharmacol Ther 80:75-84.

Loos U, Musch E, Jensen JC, Mikus G, Schwabe HK, and Eichelbaum M (1985) Pharmacokinetics of oral and intravenous rifampicin during chronic administration. Klin Wochenschr 63:1205-1211.

Lutz JD, Kirby BJ, Wang L, Song Q, Ling J, Massetto B, Worth A, Kearney BP, and Mathias A (2018) Cytochrome P450 3A induction predicts P-glycoprotein induction; Part 1: establishing induction relationships using ascending dose rifampin. Clin Pharmacol Ther 104:1182-1190.

Maeda K, Ikeda Y, Fujita T, Yoshida K, Azuma Y, Haruyama Y, Yamane N, Kumagai Y, and Sugiyama Y (2011) Identification of the rate-determining process in the hepatic clearance of atorvastatin in a clinical cassette microdosing study. Clin Pharmacol Ther 90:575-581.

Mao J, Martin I, McLeod J, Nolan G, van Horn R, Vourvahis M, and Lin YS (2017) Perspective: $4 \beta$-hydroxycholesterol as an emerging endogenous biomarker of hepatic CYP3A. Drug Metab Rev 49:18-34.

Marschall HU, Wagner M, Zollner G, Fickert P, Diczfalusy U, Gumhold J, Silbert D, Fuchsbichler A, Benthin L, Grundström R, et al. (2005) Complementary stimulation of hepatobiliary transport and detoxification systems by rifampicin and ursodeoxycholic acid in humans. Gastroenterology 129:476-485.

Meyer Zu Schwabedissen HE, Böttcher K, Chaudhry A, Kroemer HK, Schuetz EG, and Kim RB (2010) Liver X receptor $\alpha$ and farnesoid X receptor are major transcriptional regulators of OATP1B1. Hepatology 52:1797-1807.

Meyer zu Schwabedissen HE, Tirona RG, Yip CS, Ho RH, and Kim RB (2008) Interplay between the nuclear receptor pregnane $\mathrm{X}$ receptor and the uptake transporter organic anion transporter polypeptide 1A2 selectively enhances estrogen effects in breast cancer. Cancer Res 68:9338-9347.

Mori D, Ishida H, Mizuno T, Kusumoto S, Kondo Y, Izumi S, Nakata G, Nozaki Y, Maeda K, Sasaki Y, et al. (2020) Alteration in the plasma concentrations of endogenous organic anion-transporting polypeptide 1B biomarkers in patients with non-small cell lung cancer treated with paclitaxel. Drug Metab Dispos 48:387-394. Murray M and Zhou F (2017) Trafficking and other regulatory mechanisms for organic anion transporting polypeptides and organic anion transporters that modulate cellular drug and xenobiotic influx and that are dysregulated in disease. Br J Pharmacol 174:1908-1924.

Niemi M (2007) Role of OATP transporters in the disposition of drugs. Pharmacogenomics 8:787-802.

Niemi M, Backman JT, Fromm MF, Neuvonen PJ, and Kivistö KT (2003) Pharmacokinetic interactions with rifampicin: clinical relevance. Clin Pharmacokinet 42.819-850.

Niu C, Wang Y, Zhao X, Tep S, Murakami E, Subramanian R, Smith B, and Lai Y 2019) Organic anion-transporting polypeptide genes are not induced by the pregnane X receptor activator rifampin: studies in hepatocytes in vitro and in monkeys in vivo. Drug Metab Dispos 47:1433-1442.

Oscarson M, Zanger UM, Rifki OF, Klein K, Eichelbaum M, and Meyer UA (2006) Transcriptional profiling of genes induced in the livers of patients treated with carbamazepine. Clin Pharmacol Ther 80:440-456.

Patilea-Vrana GI and Unadkat JD (2018) When does the rate-determining step in the hepatic clearance of a drug switch from sinusoidal uptake to all hepatobiliary clearances? Implications for predicting drug-drug interactions. Drug Metab Dispos 46:1487-1496

Rodrigues AD, Lai Y, Shen H, Varma MVS, Rowland A, and Oswald S (2020) Induction of human intestinal and hepatic organic anion transporting polypeptides: where is the evidence for its relevance in drug-drug interactions? Drug Metab Dispos 48:205-216.

Shen H, Dai J, Liu T, Cheng Y, Chen W, Freeden C, Zhang Y, Humphreys WG, Marathe P, and Lai Y (2016) Coproporphyrins I and III as functional markers of OATP1B activity: in vitro and in vivo evaluation in preclinical species. $J$ Pharmacol Exp Ther 357:382-393.

Shen H, Yang Z, Mintier G, Han YH, Chen C, Balimane P, Jemal M, Zhao W, Zhang R, Kallipatti S, et al. (2013) Cynomolgus monkey as a potential model to assess drug interactions involving hepatic organic anion transporting polypeptides: in vitro, in vivo, and in vitro-to-in vivo extrapolation. J Pharmacol Exp Ther 344:673-685.

Shitara Y, Maeda K, Ikejiri K, Yoshida K, Horie T, and Sugiyama Y (2013) Clinical significance of organic anion transporting polypeptides (OATPs) in drug disposition: their roles in hepatic clearance and intestinal absorption. Biopharm Drug Dispos 34:45-78.

Sinz M, Wallace G, and Sahi J (2008) Current industrial practices in assessing CYP450 enzyme induction: preclinical and clinical. AAPS $J$ 10:391-400.

Sinz MW (2013) Evaluation of pregnane X receptor (PXR)-mediated CYP3A4 drugdrug interactions in drug development. Drug Metab Rev 45:3-14.

Staudinger JL, Woody S, Sun M, and Cui W (2013) Nuclear-receptor-mediated regulation of drug- and bile-acid-transporter proteins in gut and liver. Drug Metab Rev 45:48-59.

Strolin Benedetti M and Dostert P (1994) Induction and autoinduction properties of rifamycin derivatives: a review of animal and human studies. Environ Health Perspect 102 (Suppl 9):101-105.

Tahara H, Watanabe M, and Hasegawa M (2019) A comparative study for detecting CYP3A induction by CYP3A probe drugs and endogenous markers in cynomolgus monkeys. Biopharm Drug Dispos 40:81-93.

Takahashi T, Uno Y, Yamazaki H, and Kume T (2019) Functional characterization for polymorphic organic anion transporting polypeptides (OATP/SLCO1B1, 1B3, 2B1) of monkeys recombinantly expressed with various OATP probes. Biopharm Drug Dispos 40:62-69.

Takehara I, Watanabe N, Mori D, Ando O, and Kusuhara H (2019) Effect of rifampicin on the plasma concentrations of bile acid-O-sulfates in monkeys and human liver-transplanted chimeric mice with or without bile flow diversion. $J$ Pharm Sci 108:2756-2764

Türk D, Hanke N, Wolf S, Frechen S, Eissing T, Wendl T, Schwab M, and Lehr T (2019) Physiologically based pharmacokinetic models for prediction of complex CYP2C8 and OATP1B1 (SLCO1B1) drug-drug-gene interactions: a modeling network of gemfibrozil, repaglinide, pioglitazone, rifampicin, clarithromycin and itraconazole. Clin Pharmacokinet 58:1595-1607.

Ufuk A, Kosa RE, Gao H, Bi YA, Modi S, Gates D, Rodrigues AD, Tremaine LM, Varma MVS, Houston JB, et al. (2018) In vitro-in vivo extrapolation of OATP1Bmediated drug-drug interactions in cynomolgus monkey. J Pharmacol Exp Ther 365:688-699.

Watanabe T, Kusuhara H, Maeda K, Kanamaru H, Saito Y, Hu Z, and Sugiyama Y (2010) Investigation of the rate-determining process in the hepatic elimination of HMG-CoA reductase inhibitors in rats and humans. Drug Metab Dispos 38 $215-222$. 
Zamek-Gliszczynski MJ, Patel M, Yang X, Lutz JD, Chu X, Brouwer KLR, Lai Y, Lee CA, Neuhoff S, Paine MF, et al. (2020) Intestinal P-gp and putative hepatic OATP1B induction: international transporter consortium perspective on drug development implications. Clin Pharmacol Ther DOI: 10.1002/cpt.1916 [published ahead of print].

Zhang W, Deng S, Chen XP, Zhou G, Xie HT, He FY, Cao D, Li YJ, and Zhou HH (2008) Pharmacokinetics of rosuvastatin when coadministered with rifampicin in healthy males: a randomized, single-blind, placebo-controlled, crossover study. Clin Ther 30:1283-1289.
Zhang Y, Panfen E, Fancher M, Sinz M, Marathe P, and Shen H (2019) Dissecting the contribution of OATP1B1 to hepatic uptake of statins using the OATP1B1 selective inhibitor estropipate. Mol Pharm 16:2342-2353.

Address correspondence to: Dr. Hong Shen, Senior Principal Scientist, Department of Metabolism and Pharmacokinetics (MAP), Pharmaceutical Candidate Optimization (PCO), Bristol Myers Squibb Company, Route 206 and Province Line Rd., Princeton, NJ 08543. E-mail: hong.shen1@bms.com 